\title{
Retinopathy of Prematurity, a Study of Prevalence and Risk Factors
}

Ibraheem Sameeh Awad, ${ }^{1}$ MBBCH, Ali Abd Al-Latif Afia, ${ }^{1}$ MD, Abd El-Sattar Abdullah El-Sayeh, ${ }^{1}$ MD, Mahmoud Mohammed Ahmed Ali, ${ }^{2}$ MD, El Sayed Hamed Fahmy Abo Zied, ${ }^{1}$ MD.

* Corresponding Author:

Ibraheem Sameeh Awad

ibrahimsamih88@gmail.com

Received for publication

September 4, 2021; Accepted

October 25, 2021; Published

online October 25, 2021.

\section{Copyright The Authors published by Al-Azhar} University, Faculty of Medicine, Cairo, Egypt. Users have the right to read, download, copy, distribute, print, search, or link to the full texts of articles under the following conditions: Creative Commons AttributionShare Alike 4.0 International Public License (CC BY-SA 4.0).

doi: $10.21608 /$ aimj.2021.94188.1565

${ }^{1}$ Pediatrics Department, Faculty of Medicine, Al-Azhar University, Cairo, Egypt.

${ }^{2}$ Ophthalmology Department Faculty of Medicine, Al-Azhar University, Cairo, Egypt.

\begin{abstract}
Background: Premature term infants are commonly impacted by retinopathy of prematurity (ROP), a blinding illness. The most significant risks are low birth weight, preterm and oxygen treatment for prolonged period.

Aim of the study: To assess the frequency of ROP in premature infants and to determine the hazard factors that lead to retinopathy of prematurity.

Patients and Methods: In this research, 100 preterm infants were hospitalized to Al-Azhar University Hospitals' NICU. Clinical examination was done included weight, gestational age, vital signs, , CNS, chest, heart and abdominal examination .Local eye examination was done by according to specific protocol. All findings were documented with RetCam.

Results: This study included 100 newborn infants, of them 22 cases affected with ROP and 78 cases were free. There were 11 cases of ROP at stage I, 8 cases of ROP at stage II , and 3 cases of ROP at stage III. Lower gestational age, lower birth weight, sepsis, receiving oxygen treatment and its duration and intraventricular hemorrhage were all important risk factors for ROP development. While non significant risk factors were sex, mode of delivery, phototherapy and patent ductus arteriosus

Conclusion: Short gestational age, reduced birth weight, neonatal sepsis, and oxygen treatment for a period $>1$ week are all important risk factors for ROP. Early screening and appropriate treatment are necessary to prevent blindness from ROP.

Keywords: Retinopathy of prematurity; retrolental fibroplasia ; Ret Cam.

Disclosure: The authors have no financial interest to declare in relation to the content of this article. The Article Processing Charge was paid for by the authors.

Authorship: All authors have a substantial contribution to the article.
\end{abstract}

\section{INTRODUCTION}

Terry initially described Retinopathy of Prematurity (ROP) in 1942, calling it Retrolental Fibroplasia at that time. ${ }^{1}$

At the beginning, disease was not commonly seen, but nowadays it affects thousands of children worldwide. $^{2}$

Early screening of newborn infants at risk for developing (ROP) is critical to avoid serious complications that may reach up to blindness.$^{3}$

Several risk factors are associated with occurrence of (ROP), like prematurity, reduced birth weight and need for oxygen treatment for prolonged time. ${ }^{4}$

Retinopathy of prematurity is classified into 5 stages , stage 1 is characterized by a faint demarcation line, stage 2 by a raised ridge, stage 3 by extraretinal fibrovascular tissue, stage 4 by a subtotal retinal detachment and stage 5 by a total retinal detachment. Plus disease is characterized by an increase in arteriolar tortuosity as well as venous engorgement in the vessels of the posterior pole. 5

Patients' visual results have enhanced after receiving early therapy with laser photocoagulation and treatment with anti-VEGF (vascular endothelial growth factor). ${ }^{6}$

Prevention of (ROP) requires a multidisciplinary approach beginning in early and continuing throughout childhood. ${ }^{6}$

We aimed to evaluate the prevalence of ROP in premature infants, as well as to determine the risk factors that lead to retinopathy of prematurity.

\section{PATIENTS AND METHODS}

This prospective study of 100 newborn infants was admitted to Al-Azhar University Hospitals' Neonatal Intensive Care Unit (NICU)., Egypt between January 2020 and May 2021. 
All participants enrolled in the research were given written consent. The approval of the research was achieved from Al-Azhar Faculty of Medicine (Research Ethics Committee (REC).

Inclusion Criteria: Premature newborn infants with reduced birth weight, low gestational age, sepsis, oxygen treatment, blood transfusion, intraventricular hemorrhage and mechanical ventilation.

Exclusion Criteria: Newborn infants admitted at NICU that do not have the above mentioned risk factors .

Methods:

History: Perinatal history; discover risk factors such as perinatal asphyxia and prematurity.

Clinical examination: Weight, length, head circumference, gestational age , vital signs, neonatal reflexes, CNS, chest, heart, and abdominal examination

\section{Occular examination :}

Beginning with the fourth postnatal week, infants were checked at 1-2 week intervals
With the RetCam, ophthalmologist checks the posterior pole with special attention to vessel characteristics (tortuosity and dilatation)to identify the presence or not of Plus Disease, at the same time observe the extent of vascularization, with which we can establish the Zone of Retinal Vascularization (I, II or III).

\section{Statistical analysis}

Version 20.0 of IBM SPSS software was used to analyze the data that entered into the computer.

\section{RESULTS}

\begin{tabular}{|c|c|c|c|}
\hline & & No. & $\%$ \\
\hline $\begin{array}{l}\text { Retinopathy of } \\
\text { (ROP) }\end{array}$ & Prematurity & & \\
\hline No & & 78 & 78.0 \\
\hline Yes & & 22 & 22.0 \\
\hline
\end{tabular}

Table 1: Prevalence of ROP among studied cases according to RetCam findings $(n=100)$ Of 100 new born infants included in the study, there were 22 cases suffering from ROP, there were 11 instances classified as stage I, 8 cases classified as stage II, and 3 cases classified as stage III.

Pupillary dilatation for the evaluation of the (central and peripheral) retina using cyclopentolate hydrochloride eye drops .

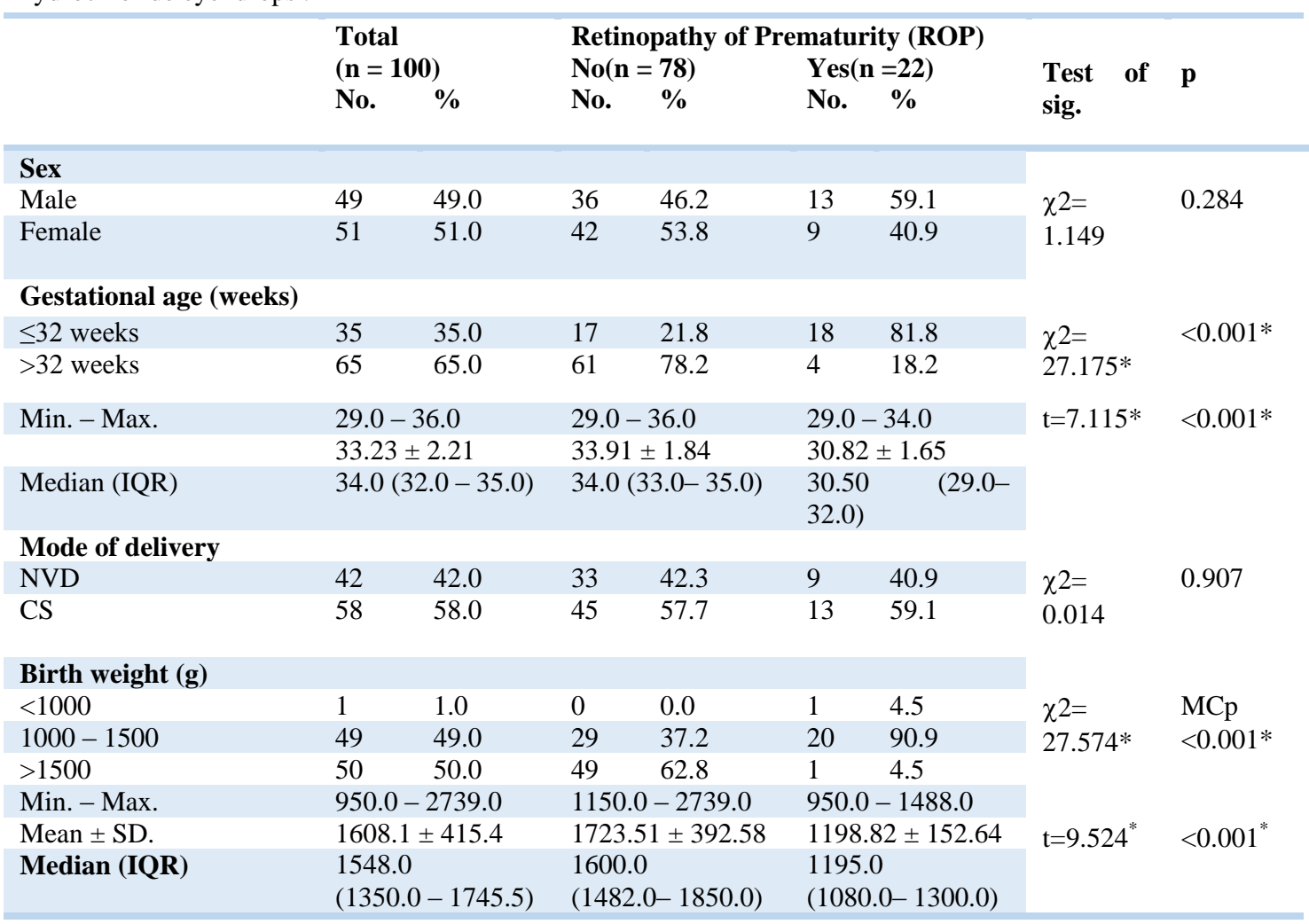

Table 2: Comparing the demographic data of the studied groups $(n=100)$. There were significant differences in gestational age and birth weight among the groups studied in our study, but no significant differences in sex or mode of delivery. ( $\chi^{2}$ : Chi square test; MC: Monte Carlo; $t$ : Student $t$-test; $p$ : $p$ value for comparing between the studied groups; *: Statistically significant at $\mathrm{p} \leq 0.05$; IQR: Interquartile range; SD: Standard deviation) 


\begin{tabular}{|c|c|c|c|c|c|c|c|c|}
\hline & \multicolumn{2}{|c|}{$\begin{array}{l}\text { Total } \\
(n=100)\end{array}$} & \multicolumn{2}{|c|}{$\begin{array}{l}\text { Retinopathy } \\
\text { (ROP) }\end{array}$} & \multicolumn{2}{|c|}{ Prematurity } & \multirow[t]{3}{*}{$\chi^{2}$} & \multirow[t]{3}{*}{$\mathbf{p}$} \\
\hline & & & \multicolumn{2}{|c|}{$\operatorname{No}(n=78)$} & \multicolumn{2}{|c|}{$\operatorname{Yes}(n=22)$} & & \\
\hline & No. & $\%$ & No. & $\%$ & No. & $\%$ & & \\
\hline Respiratory distress syndrome & 83 & 83.0 & 61 & 78.2 & 22 & 100.0 & $5.777 *$ & $\mathrm{FEp}=0.020 *$ \\
\hline Sepsis & 57 & 57.0 & 38 & 48.7 & 19 & 86.4 & $9.922 *$ & $0.002 *$ \\
\hline Patent ductus arteriosus & 3 & 3.0 & 2 & 2.6 & 1 & 4.5 & 0.231 & $\mathrm{FEp}=0.530$ \\
\hline Intraventricular hemorrhage & 12 & 12.0 & 2 & 2.6 & 10 & 45.5 & $24.466 *$ & FEp $<0.001 *$ \\
\hline Hypotension & 23 & 23.0 & 13 & 16.7 & 10 & 45.5 & $8.030 *$ & $0.005^{*}$ \\
\hline Phototherapy & 90 & 90.0 & 71 & 91.0 & 19 & 86.4 & 0.414 & $\mathrm{FEp}=0.687$ \\
\hline
\end{tabular}

Table 3: Comparing the groups studied based on different risk factors $(n=100)$. $\mathrm{mIn}$ our research, we discovered significant differences among the two groups in terms of respiratory distress, intraventricular hemorrhage, and hypotension, but not in terms of patent ductus arteriosus. ( $\chi^{2}$ : Chi square test; FE: Fisher Exact; p: p value for comparing between the studied groups; *: Statistically significant at $\mathrm{p} \leq 0.05$; IQR: Interquartile range; SD: Standard deviation)

\begin{tabular}{|c|c|c|c|c|c|c|c|c|}
\hline & \multirow{2}{*}{\multicolumn{2}{|c|}{$\begin{array}{l}\text { Total } \\
(n=100)\end{array}$}} & \multicolumn{4}{|c|}{ Retinopathy of Prematurity (ROP) } & \multirow[t]{3}{*}{$\chi^{2}$} & \multirow[t]{3}{*}{$\mathbf{p}$} \\
\hline & & & \multicolumn{2}{|c|}{$\operatorname{No}(n=78)$} & \multicolumn{2}{|c|}{$\operatorname{Yes}(n=22)$} & & \\
\hline & No. & $\%$ & No. & $\%$ & No. & $\%$ & & \\
\hline \multicolumn{9}{|l|}{ Oxygen therapy } \\
\hline No & 29 & 29.0 & 27 & 34.6 & 2 & 9.1 & \multirow[t]{2}{*}{$5.430 *$} & \multirow[t]{2}{*}{$0.020^{*}$} \\
\hline Yes & 71 & 71.0 & 51 & 65.4 & 20 & 90.9 & & \\
\hline \multicolumn{9}{|c|}{ Duration of oxygen therapy } \\
\hline No oxygen therapy & 29 & 51 & 27 & 34.6 & 2 & 9.1 & \multirow[t]{3}{*}{$77.889 *$} & \multirow[t]{3}{*}{$<0.001 *$} \\
\hline$<1$ week & 51 & 51.0 & 50 & 64.1 & 1 & 4.5 & & \\
\hline$>1$ week & 20 & 20.0 & 1 & 1.3 & 19 & 86.4 & & \\
\hline
\end{tabular}

Table 4: Comparing of the study groups based on oxygen therapy $(n=100)$. Receiving oxygen therapy and its duration differed significantly between the groups in our study. $\left(\chi^{2}\right.$ : Chi square test; $p$ : $p$ value for comparing between the studied groups; *: Statistically significant at $\mathrm{p} \leq 0.05$; IQR: Interquartile range; SD: Standard deviation).

\begin{tabular}{|c|c|c|c|c|}
\hline & \multicolumn{2}{|c|}{ Univariate } & \multicolumn{2}{|c|}{ \#Multivariate } \\
\hline & $\mathbf{p}$ & OR (95\% C.I) & $\mathbf{P}$ & OR (95\% C.I) \\
\hline Sex (Male) & 0.286 & $1.685(0.646-4.399)$ & & \\
\hline Gestational age (weeks) & $<0.001 *$ & $0.453(0.327-0.629)$ & 0.887 & $0.917(0.277-3.034)$ \\
\hline Mode of delivery (CS) & 0.907 & $1.059(0.405-2.770)$ & & \\
\hline Birth weight (g) & $0.001 *$ & $0.028(0.004-0.219)$ & $0.022 *$ & $0.982(0.966-0.997)$ \\
\hline Respiratory distress syndrome & 0.998 & - & & \\
\hline Sepsis & $0.004^{*}$ & $6.667(1.824-24.366)$ & $0.028^{*}$ & $\begin{array}{l}\text { 685.142(1.990 } \\
235871.6)\end{array}$ \\
\hline Patent ductus arteriosus & 0.635 & $1.810(0.156-20.940)$ & & \\
\hline Intraventricular hemorrhage & $<0.001 *$ & $\begin{array}{l}31.667(6.169 \\
162.548)\end{array}$ & $0.037 *$ & $\begin{array}{l}1335.280(1.548 \\
1151784.2)\end{array}$ \\
\hline Hypotension & $0.007 *$ & $4.167(1.489-11.660)$ & 0.160 & $10.747(0.393-294.15)$ \\
\hline Phototherapy & 0.523 & $0.624(0.147-2.646)$ & & \\
\hline Oxygen therapy & $0.032 *$ & $5.294(1.150-24.365)$ & $0.041^{*}$ & $\begin{array}{l}2455.233(1.381 \\
4363573.6)\end{array}$ \\
\hline
\end{tabular}

Table 5: For the parameters impacting ROP, we used univariate as well as multivariate logistic regression analyses $(n=22)$. Based on univariate analysis, this table shows the development of ROP risk factors. ROP infants had significantly lower GA and BW. ROP risk increased with sepsis, intraventricular hemorrhage, hypotension and receiving oxygen therapy. While in the multivariate analyses of risk factors for ROP, significant variables included birth, sepsis, intraventricular hemorrhage, and receiving oxygen therapy, and nonsignificant variables were sex, mode of delivery, patent ductus arteriosus, and phototherapy. (OR: Odd's ratio C.I: Confidence interval; LL: Lower limit; UL: Upper Limit; \#: All variables with $\mathrm{p}<0.05$ was included in the multivariate *: Statistically significant 


\section{Cases:}

\section{Case 1}

Female preterm weighing 1100 grams, gestational age of 29 weeks treated at 36th weeks of post menstrual age, she was in stage 3 of ROP, with plus disease in zone II. She received only one injection of RANIBIZUMAB Frquent follow up visits showed no recurrence and visits continued till complete recover (Figure 1).

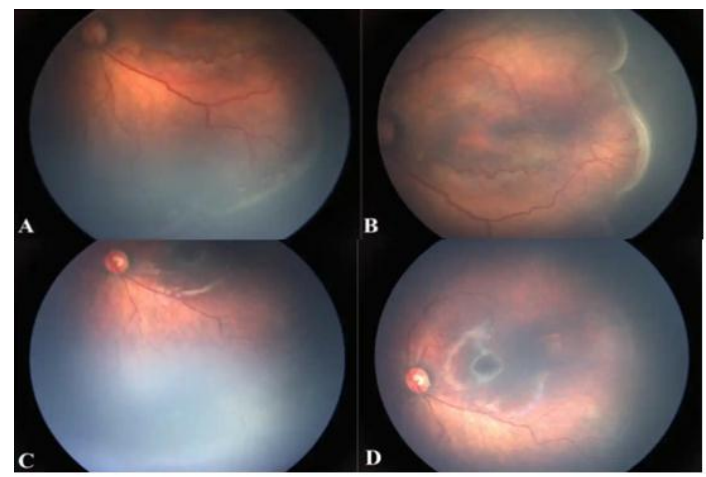

Fig 1: A,B show stage III, Plus disease in zone II ROP. C,D show regression of plus disease ,ridge 55 weeks after injection of Ranibizumab.

\section{Case 2}

Male preterm weighing 900 grams at gestational age of 30 weeks . examined at 34 weeks, and ROP status was zone II-III , stage 3 with plus disease ; therefore , he was seen after 1 week and no regression was present, treated by laser photocoagulation in both eyes . Frquent postoperative follow up visits showed no recurrence and continued till complete recovery (Figure 2).

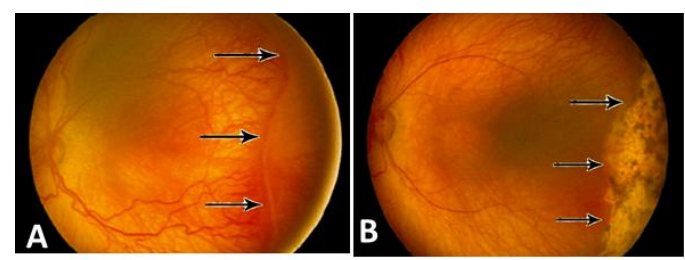

Fig 2: A: It shows stage III , zone II - III ROP with plus disease. B: It shows Post laser ablative treatment and chorioretinal scarring with involution of neovasculature.

\section{DISCUSSION}

Many risk factors, such as oxygen therapy, sepsis, intraventricular haemorrhage, hypotension, congenital heart disease, phototherapy and blood transfusion, predispose to ROP.

The current study included 100 cases, there were 22 $(22 \%)$ cases suffered from ROP while 78 infants $(78.0 \%)$ were free.Of the 22 cases that suffered from ROP , there were 11 cases of ROP in stage I, 8 cases of ROP in stage II, and 3 cases of ROP in stage III .
Regarding demographic data of the studied groups showed that free group included 36 male $(46.2 \%)$ and 42 females $(53.8 \%)$ while among ROP group there was 13 male $(59.1 \%)$ and 9 females $(40.9 \%)$ with no statistically significant difference between the two groups.

Furthermore, gestational age of free infants ranged from 29.0 - 36.0 week with mean \pm SD was $33.23 \pm$ 2.21 week while gestational age of infants with ROP ranged from $29.0-34.0$ week with a mean \pm SD of $30.82 \pm 1.65$ week which was statistically significant smaller gestational age at p-value $<0.001 *$.

In a study of 310 infants, Alizadeh $\mathrm{Y}$ et al found that ROP was detected in 64 (20.6\%) of referred preterm infants (95\% CI: $17.7 \%-23.5 \%$ ); this comprised stage I disease in $48 \%$, stage 2 disease in $29 \%$, and stage 3 or higher disease in $23 \%$ of the cases.

The ROP-affected infants had an average gestational age (GA) of $30.18 \pm 2.28$ weeks and a birth weight $(\mathrm{BW})$ of $1,422.8 \pm 420.8 \mathrm{~g}$. ROP risk factors included low BW, low GA, oxygen treatment, apnea, phototherapy, and blood transfusion. Only low BW and low GA were found to be independently related to the condition following logistic regression analysis $^{7}$.

In the current research regarding the birth weight of infants with ROP ranged from 950.0 - 1488.0 with a mean of $1198.82 \pm 152.64$ thus, ROP cases showed statistically significant lower birth weight rather than free infants at $\mathrm{p}$-value $<0.001^{*}$.

Gebeşçe A et al. carried out a study on 219 premature infants were retrospectively screened for retinopathy. The infants involved in the study had gestational ages varying from 25 to $36 \mathrm{wk}$, with birth weights varying between 670 and $4460 \mathrm{~g}$. ROP was found in $20.1 \%$ (44) of preterm infants in this study, with 16 having stage $1(36.4 \%), 15$ having stage 2 $(34.1 \%), 11$ having stage $3(25 \%), 1$ having stage 4 $(2.3 \%), 1$ having stage $5(2.3 \%)$, and 6 having plus (+) disease $(7.2 \%)$. Low birth weight as well as ventilation therapy were both risk factors for developing of ROP. ${ }^{8}$

This result is consistent with the findings of the Waheeb study, which found that no threshold ROP was present in children who weighed more than 1250 g 9 . Other researchers have proposed decreasing the BW and GA thresholds to fewer than $1000 \mathrm{~g}$ and 28 wk, respectively..$^{0}$

The current study found no statistically significant differences between free and ROP infants, with a pvalue of 0.90 .

In the present study among 22 infants with ROP 20 cases (90\%) received oxygen therapy where 19 received therapy for duration $>1$ week and 1 received therapy for duration $<1$ week with a statistically significant difference regarding receiving 
oxygen therapy and duration of it at p-value 0.020 and $0.001^{*}$ respectively.

Anemia of prematurity is defined as a reduction in $\mathrm{Hb}$ concentration following birth caused by impaired erythropoiesis owing to insufficient EPO production. Blood transfusion, recombinant EPO to prevent or treat anemia, and anemia itself have all been linked as ROP risk factors. ${ }^{11}$

Our data showed that only 4 infants received a blood transfusion once they all were free from ROP and no one from ROP cases received a blood transfusion with no statistically significant difference between the two studied groups at a p-value of 0.573 .

However, in the current study, patent ductus arteriosus occurred in only 1 ROP case $(4.5 \%)$ and in 2 infants $(2.6 \%)$ free of ROP with no statistically significant difference between the two studied groups at a p-value of 0.530 .

Intraventricular hemorrhage (IVH) is a common premature delivery complication which causes neurodevelopmental impairments. In the current study, IVH occurred in 10 ROP cases $(45.5 \%)$ with a statistically significant difference between the two studied groups at $\mathrm{p}$-value $<0.001 *$.

Also, there was a statistically significant difference between the two studied groups regarding the presence of hypotension at $\mathrm{p}$-value $<0.005 .^{12}$

In the same regard, Ali et al. performed a retrospective cohort analysis of 108 premature infants that had been examined for ROP, which was found in 75 of them. ROP was independently related with late-onset sepsis, ventilation, and hypercapnia. Patients with severe treatable ROP had a lower birth weight (1200 g, ranging from $980-1590 \mathrm{~g}$ vs $1460 \mathrm{~g}$, ranging from $770-2475 \mathrm{~g}, \mathrm{p}=0.029$ ) and a shorter gestational age than others who did not have ROP or had mild or moderate ROP (29 weeks, ranging from 27-33 weeks vs 32 weeks, ranging from 28-36 weeks, $\mathrm{p}=0.002$ ). The length of stay, time spent on incubator oxygen, delayed sepsis, and intraventricular hemorrhage were all risk factors for severe ROP that could be treated. ${ }^{13}$

Araz-Ersan B et al. conducted a research on 2950 preterm infants who had ROP screenings.

The average GA for infants with severe ROP was $31.2 \pm 2.7$ weeks and an average BW of $1543.4 \pm 508.3$ g. The risk factor analysis of hospitalized infants found that $\mathrm{BW}<1500 \mathrm{~g}, \mathrm{GA}<32$ weeks, intraventricular hemorrhage, respiratory distress syndrome, apnea, sepsis, as well as phototherapy were related with an increased prevalence of ROP. Furthermore, sepsis, male gender, multiple gestations, and a BW of $<1500 \mathrm{~g}$ were all linked to an increased risk of severe ROP progression, which matches our results.$^{1^{4}}$
The prevalence of ROP in the studied population was $44.5 \%$ (95\% confidence interval, $\mathrm{CI}=35.6-46.1)$, according to Gonçalves $\mathrm{E}$ et al. The risk variables for developing the disease were as follows: $\mathrm{BW}<1,000$ $\mathrm{g}$ (odds ratio, $\mathrm{OR}=4.14 ; 95 \% \mathrm{CI}=1.34-12.77$ ); $\mathrm{GA}$ $<30 \mathrm{wk}(\mathrm{OR}=6.69 ; 95 \% \mathrm{CI}=2.10-21.31)$; usage of blood derivatives $(\mathrm{OR}=4.14 ; 95 \% \mathrm{CI}=2.99-8.99)$; and occurrence of sepsis $(\mathrm{OR}=1.99 ; 95 \% \mathrm{CI}=1.45$ $2.40)$ and this contradicts our results. ${ }^{15}$

A univariate analysis of ROP development risk variables was used in this study. Infants with ROP had significantly reduced GA and BW than those without ROP. ROP risk increased with sepsis (OR $6.667 ; 95 \%$ C. I), intraventricular hemorrhage (OR 31.667 ; 95\%C. I) and hypotension (OR 4.167; $95 \% \mathrm{C}$. I) that were significantly more common among infants with ROP. In addition, receiving oxygen therapy was significantly more common among infants with ROP (OR 31.667; 95\%C. I; P = $0.032^{*}$ )

A total of 5,718 VLBW infants (844 instances with maternal preeclampsia) have been included in the Huang HC et al study for analysis. Mild and severe ROP were found to be prevalent in $36.0 \%$ and $12.2 \%$, respectively. Reduced GA and BW, vaginal birth, non-SGA, RDS, PDA, sepsis, transfusions, and the absence of maternal preeclampsia were all found to be linked with mild and severe ROP progression in univariable analysis..$^{6}$

After controlling for numerous possible confounders, the multivariate analysis of risk variables for ROP progression employing a stepwise procedure in the current study indicated that birth weight $(P=0.022)$, sepsis $(\mathrm{P}=0.028)$, intraventricular hemorrhage $(\mathrm{P}=$ $0.037)$, and receiving oxygen therapy $(\mathrm{P}=0.041)$ were significant variables.

Nonsignificant variables included sex (male), mode of delivery (CS), Patent ductus arteriosus, Respiratory distress syndrome, and usage of Phototherapy and this is in agreement with our findings.

Overall, our data suggest that birth weight, receiving oxygen therapy, and neonatal sepsis are independent risk factors for ROP development.

\section{CONCLUSION}

Low birth weight, low gestational age, neonatal sepsis and oxygen therapy for a period $>1$ week are all significant risk factors for retinopathy of prematurity. Early screening and appropriate therapy are necessary to avoid blindness from ROP.

\section{REFERENCES}

1. Bashinsky AL. Retinopathy of prematurity. North Carolina medical journal. 2017;78(2): 124-8. 
2. Hameed B, Shyamanur K, Kotecha S, et al. Trends in the Incidence of Severe Retinopathy of Prematurity in a Geographically Defined Population Over a $10-$ Year Period. PediatricsD. $2010 ; 113(6)$ : 1653.

3. Dogra MR, Katoch D and Dogra M. An update on retinopathy of prematurity (ROP). The Indian Journal of Pediatrics. 2017;84(12): 930-6.

4. Feldkamp ML, Carey JC, Byrne JL, et al. Etiology and clinical presentation of birth defects: population based study. Bmj. 2017;76(4):105-106.

5. Chawla D, Agarwal R, Deorari AK, et al Retinopathy of prematurity. The Indian Journal of Pediatrics. 2008; 75(1): 73-6.

6. UNICEF.: Children in Egypt: a statistical digest UNICEF Egypt, Cairo, Egypt. 2015;23(3): 130-7.

7. Alizadeh Y, Zarkesh M, Moghadam RS, et al. Incidence and risk factors for retinopathy of prematurity in North of Iran. Journal of ophthalmic \& vision research. 2015;10(4): 424.

8. Gebeşçe A, Uslu H, Keleş E, et al. Retinopathy of prematurity: incidence, risk factors, and evaluation of screening criteria. Turkish journal of medical sciences. 2016; 46(2): 315-20.

9. Waheeb $\mathrm{S}$ and Alshehri K. Incidence of retinopathy of prematurity at two tertiary centers in Jeddah, Saudi Arabia. Saudi Journal of Ophthalmology. 2016; 30(2): 109-12.

10. Wirth M, Desjarlais M, Chemtob S, et al. Multifactorial contributions to WINROP to enhance prediction of severe retinopathy of prematurity. Acta Paediatrica. 2019 ; 108(6): 1170.

11. Kim SJ, Port AD and Swan R. Rretinopathy of prematurity : a review of risk factors and their clinical significance. Survey of ophthalmology. $2018 ; 63(5)$ : 618-37.

12. Mukerji A, Shah V and Shah PS. :Periventricular/intraventricular hemorrhage and neurodevelopmental outcomes: a metaanalysis. Pediatrics journal. 2015 ;136(6): 113243.

13. Ali AA, Gomaa NA, Awadein AR et al. Retrospective cohort study shows that the risks for retinopathy of prematurity included birth age and weight, medical conditions and treatment. Acta Paediatrica. 2017;106(12): 1919-27.

14. Araz-Ersan B, Kir N, Akarcay K, AydinogluCandan $\mathrm{O}$, et al. Epidemiological analysis of retinopathy of prematurity in a referral centre in Turkey. British journal of ophthalmology. 2013; 97(1): 15-7.
15. Gonçalves E, Násser LS, Martelli DR, et al. Incidence and risk factors for retinopathy of prematurity in a Brazilian reference service. Sao Paulo Medical Journal. 2014 ; 132, 85-91.

16. Huang HC, Yang HI, Chou HC, et al. Preeclampsia and retinopathy of prematurity in very-low-birth-weight infants: a population-based study. Journal of ophthalmology and strabismus. 2015 ; 10(11): 143248. 